\title{
Amlodipine Induced Severe Pedal Edema: A Case Report from a Tertiary Care Hospital
}

Sanghavi $\mathbf{K}^{1}$, Someshwari $\mathbf{M}^{1}$, Rajanandh $\mathbf{M G}^{2^{*}}$ and Seenivasan $\mathbf{P}^{2}$

${ }^{1}$ Sri Ramachandra University, Porur, Chennai, India

${ }^{2}$ Department of Pharmacy Practice, Sri Ramachandra University, Porur, Chennai, India

"Corresponding author: Rajanandh MG, Department of Pharmacy Practice, Faculty of Pharmacy, Sri Ramachandra University, Porur, Chennai, India, Tel: 04143230123; E-mail: mgrpharm@gmail.com

Received date: Sep 07, 2017; Accepted date: Oct 11, 2017; Published date: Oct 18, 2017

Copyright: (c) 2017 Sanghavi K, et al. This is an open-access article distributed under the terms of the Creative Commons Attribution License, which permits unrestricted use, distribution, and reproduction in any medium, provided the original author and source are credited.

\begin{abstract}
Amlodipine is a fourth generation dihydropyridine derivative calcium channel blocker, mainly used in the treatment of hypertension, angina and certain other cardiac disorders. It is an L-type Ca2+ channel blocker, which leads to inhibitory action on the sympathetic N-type Ca2+ channels. The oral bioavailability of amlodipine is between $64 \%$ and $90 \%$. The longer duration of action of amlodipine is due to a combination of high bioavailability, slow clearance and long half-life where by plasma concentration of the drug is above minimum effective concentration for a long time and show sustained efficacy. The most frequently occurring adverse effect with amlodipine therapy includes palpitation, flushing, ankle edema, hypotension, headache and nausea. PedaPI edema is a common adverse effect of calcium channel blocker (Amlodipine, Nifedipine, Diltiazem, Felodpine, Isradipine). We report a patient who developed pitting type pedal edema after treating with amlodipine for hypertension.
\end{abstract}

Keywords: Amlodipine; Glimepride; Pedal edema

\section{Case Description}

A 43 yrs old male patient was admitted to general medicine ward with complaints of swelling of the legs. On further interviewing, he was a known case of diabetes mellitus, under oral hypoglycemic agent of glimepride $2 \mathrm{mg}$ and metformin $500 \mathrm{mg}$ for past $1 \mathrm{yr}$. Before 3 months the patient was also diagnosed with hypertension and was under irregular medication.

By examining the vital sign, blood pressure was found to be $160 / 90$ $\mathrm{mmHg}$, pulse rate 78 beats per minute and all other laboratory investigations such as complete blood count, liver function test urine analysis, chest $\mathrm{X}$ ray, electrocardiograph seems to be normal. The diabetic profile shows Random blood glucose - $262 \mathrm{mg} / \mathrm{dl}$, HbA1C-7\%. From the subjective, laboratory examination and past history of the patient he was diagnosed with type II diabetes mellitus and hypertension. The patient was treated with glimepride $2 \mathrm{mg}$, metformin $500 \mathrm{mg}$ and amlodipine $2.5 \mathrm{mg}$ orally once daily. On the 4th day after initiation of amlodipine therapy, the patient was presented with pedal edema (pitting type). The physician interprets that the pedal edema was caused by amlodipine. On cessation of amlodipine the patient was recovered from edema and an alternative anti-hypertensive agent, telmisartan $40 \mathrm{mg}$ and hydrochlorothiazide $12.5 \mathrm{mg}$ once daily was prescribed.

\section{Adverse Drug Reaction (ADR) Analysis}

After collecting the past and current medication history from the patient, it was suspected that the patient had developed a drug induced pedal edema with pitting type. After analysing the ADR profiles of all drugs, it was found that the most suspected drug for producing edema was Amlodipine. We have further analyzed to establish the relationship between the drug and the observed ADRs, through causality assessment.

The ADR Probability Scale consists of 10 questions that are answered as either Yes, No or Do not know. Different point values $(-1$, $0,+1$ or +2$)$ are assigned to each answer. A simplified version of the 10 questions is provided below:

- Are there previous conclusive reports of this reaction?

- Did the adverse event appear after the drug was given?

- Did the adverse reaction improve when the drug was discontinued or a specific antagonist was given?

- Did the adverse reaction reappear upon readministering the drug?

- Were there other possible causes for the reaction?

- Did the adverse reaction reappear upon administration of placebo?

- Was the drug detected in the blood or other fluids in toxic concentrations?

- Was the reaction worsened upon increasing the dose? Or, was the reaction lessened upon decreasing the dose?

- Did the patient have a similar reaction to the drug or a related agent in the past?

- Was the adverse event confirmed by any other objective evidence?

Total scores range from -4 to +13 ; the reaction is considered definite if the score is 9 or higher, probable if 5 to 8 , possible if 1 to 4 , and doubtful if 0 or less. In the present case, a possible relationship was observed by naranjo's scale assessment.

\section{Adverse Drug Reaction Management}

Generally, management of adverse drug reaction includes withdrawal/suspension, dose reduction of suspected drug and administration of supportive therapy. Here in this case report the suspected drug amlodipine was discontinued. 
Citation: Sanghavi K, Someshwari M, Rajanandh MG, Seenivasan P (2017) Amlodipine Induced Severe Pedal Edema: A Case Report from a Tertiary Care Hospital. J Pharmacovigil 5: 243. doi:10.4172/2329-6887.1000243

Page 2 of 2

\section{Discussion}

The high efficacy and tolerability of calcium channel blockers make them as one of the first line monotherapy for the treatment of hypertension [1]. The mechanism by which amlodipine lowers the blood pressure includes, reduction in peripheral resistance thereby leading to vasodilation. Previous studies show that amlodipine is a racemic mixture of $(\mathrm{R})$ and $(\mathrm{S})$ isomers; $\mathrm{S}$ isomer has more pharmacologic effect than the $\mathrm{R}$ isomers [2]. Nausea, abdominal pain, headache, vomiting, constipation, dizziness, dry mouth, gingival hypertrophy, heartburn, photosensitivity, insomnia, light headedness, palpitation, ECG abnormalities, chest pain, hypersensitivity reaction, frequent urination and elevated liver enzyme are the most commonly occurring adverse effect with amlodipine [3]. Our case is presented with amlodipine induced severe pitting pedal edema. The mechanism considered to occur in pedal edema is due to increased hydrostatic pressure across capillaries which result in reflex constriction of post capillary vessels. The management involves cessation of the drug and substitution with an alternative antihypertensive agent [4]. In this patient, a combination of angiotensin receptor blocker and thiazide diuretic is prescribed as an alternative therapy.

\section{Conclusion}

Amlodipine induced pedal edema was reported at an incidence rate of $1.8 \%$ to $10.8 \%$ on a dose between $2.5 \mathrm{mg}$ to $10 \mathrm{mg}$ daily. The health care professionals should carefully monitor the patients while administering calcium channel blockers such as amlodipine, nifedipine, diltiazem. The early detection, discontinuation of offending drug and prescription of alternative hypertensive agent improves patient's condition.

\section{References}

1. Hatta T, Takeda K, Shiotsu Y, Sugishita C, Adachi T, et al. (2012) Switching to an L/N-type calcium channel blocker shows renoprotective effects in patients with chronic kidney disease: The Kyoto Cilnidipine Study. J Int Med Res 40:1417-1428.

2. Xu G, Wu H, Du B, Qin L (2012) The efficacy and safety of cilnidipine on mild to moderate essential hypertension: A systematic review and metaanalysis of randomized controlled trials in Chinese patients. Cardiovasc Hematol Disord Drug Targets 12: 56-62.

3. Fujita T, Ando K, Nishimura H, Ideura T, Yasuda G, et al. (2007) Antiproteinuric effect of the calcium channel blocker cilnidipine added to renin-angiotensin inhibition in hypertensive patients with chronic renal disease. Kidney Int 72: 1543-1549.

4. Rajanandh MG, Singh AP, Subramaniyan K (2013) Comparative effect of racemic amlodipine and its enantiomer with atenolol on hypertensive patients : A randomized, open, parallel group study. J Exp Clin Med 5: 217-221. 